\title{
Transcytosis of Gastrointestinal Epithelial Cells by Escherichia coli K1
}

\author{
JANE L. BURNS, ADAM GRIFFITH, JOHN J. BARRY, MECHTHILD JONAS, AND EMIL Y. CHI \\ Division of Infectious Disease, Children's Hospital and Regional Medical Center, 4800 Sand Point Way \\ N.E., CH-32, Seattle, Washington 98105, U.S.A. [J.L.B., A.G., J.J.B.]; and Departments of Pediatrics \\ [J.L.B.] and Pathology [M.J., E.Y.C.], University of Washington School of Medicine, \\ Seattle, Washington 98195, U.S.A.
}

\begin{abstract}
Escherichia coli $\mathrm{K} 1$ is an important neonatal pathogen that is usually transferred from maternal to infant gastrointestinal tract at the time of parturition. Approximately $20 \%$ of neonates are colonized, and a proportion of colonized infants goes on to have systemic infection. Entry into the bloodstream from the gastrointestinal tract is hypothesized to occur via epithelial cell invasion. Invasion of multiple epithelial cell lines was studied using gentamicin protection assays and transcytosis of polarized monolayers. Electron microscopy was used to confirm cellular invasion. Cell lines used include two human gastrointestinal lines, Caco-2 and T84; a human respiratory cell line, A549; a human laryngeal cell line, HEp-2; and a canine kidney cell line, MDCK. A virulent $E$. coli $\mathrm{K} 1$ strain, RS218, readily invaded HEp-2, A549, and T84 cell lines in gentamicin protection assays, but was
\end{abstract}

ABSTRACT

less invasive into MDCK and Caco-2 cells. RS218 also demonstrated transcytosis of both T84 and Caco- 2 cells. Four clinical isolates of E. coli $\mathrm{K} 1$ demonstrated levels of transcytosis of T84 cells similar to RS218. Caco-2 invasiveness correlated with length of time in tissue culture with maximum invasiveness demonstrated at $11 \mathrm{~d}$ in culture, when cells were polarized and differentiated. (Pediatr Res 49: 30-37, 2001)
$\mathbf{K}$, capsular antigen
ATCC, American Type Culture Collection
MEM, modified Eagle medium
CFU, colony forming units
ETEC, enterotoxigenic E. coli

Abbreviations:
Neonatal infection with Escherichia coli occurs in one in 1000 live births. Although there are $>100 \mathrm{~K}$ antigens of $E$. coli, a disproportionate number of organisms causing disease in newborn infants possess the $\mathrm{K} 1$ capsule. Approximately $20 \%$ of newborns are colonized in their stool with E. coli K1 $(1,2)$. The incidence of systemic infections caused by strains possessing the $\mathrm{K} 1$ capsule is even higher: approximately $40 \%$ of septicemia isolates and $80 \%$ of meningitis isolates from neonates are K1-producing strains (1). Colonization of neonates with $E$. coli $\mathrm{K} 1$ occurs most frequently by perinatal acquisition from the mother: $77 \%$ of infants born to K1colonized mothers had positive stool cultures for K1 by the second day of life (2). Once colonized, approximately one in 200 infants develops an invasive infection. The pathogenesis of E. coli $\mathrm{K} 1$ in bloodstream and subsequent CNS infections is not well understood. However, because the primary site of colonization is in the gastrointestinal tract, penetration of the gastrointestinal epithelium with translocation to the blood-

Received February 10, 2000; accepted July 27, 2000.

Correspondence and reprint requests: Jane L. Burns, M.D., Division of Infectious Disease, CH-32, Children's Hospital and Regional Medical Center, 4800 Sand Point Way N.E., Seattle, WA 98105, U.S.A.

Supported by National Institutes of Health grant AI32577. stream would presumably have to occur for bacteremia to develop.

Evidence of epithelial and endothelial cell invasion from in vitro experiments has been reported for meningitis-causing strains of $E$. coli K1 $(3,4)$. Epithelial cells that have been investigated include human bladder (T24), Madin Darby canine kidney (MDCK), opossum kidney (OK), and human colonic carcinoma (Caco-2) cell lines (4). In these experiments using the gentamicin protection assay to quantify invasiveness (5), T24 was the only cell line found to be invaded (4). Because gastrointestinal, not bladder, colonization appears to be the initiating event in the majority of neonates who develop invasive $E$. coli $\mathrm{K} 1$ disease (2), the lack of in vitro invasion of Caco- 2 cells, which was the only gastrointestinal cell line investigated, was a somewhat surprising result.

Despite these negative results, animal models of infection and ongoing experiments in our laboratory demonstrated invasion and were suggestive of a potential role for cell differentiation in invasion by $E$. coli $\mathrm{K} 1$ isolates. Thus, we further investigated the ability of $E$. coli $\mathrm{K} 1$ to invade multiple different epithelial cell lines both to determine whether there was a tropism for a specific epithelial cell type and to examine the role of cell differentiation. Cell lines used in these experiments 
included two human intestinal epithelial cell lines, Caco-2 and T84; a human respiratory cell line, A549; a human laryngeal carcinoma cell line, HEp-2; and a canine kidney cell line, MDCK. Experiments were performed for the gastrointestinal cell lines using both the gentamicin protection assay (5) and a transcytosis assay using cells grown in polarized monolayers (6). Because the gentamicin protection assay uses cells grown in a monolayer on plastic tissue culture plates, it does not as closely mimic the in vivo situation as does the use of polarized monolayers, in which cells are grown on membrane supports and allowed to polarize and differentiate with apical and basal membranes. The latter may be important for simulating the receptors and conditions present in the bowel lumen and may permit the demonstration of transcytosis of the intestinal mucosa. Thus we performed experiments using both techniques to assay for invasion. Invasion results were confirmed by electron microscopy.

\section{METHODS}

Bacterial strains and culture conditions. E. coli RS218 (O18:K1:H7), a well-characterized cerebrospinal fluid isolate from an infant with meningitis, was kindly provided by Dr. Richard Silver, Rochester, NY, U.S.A. (7), and was used in all experiments. This strain produces type 1 pili (8), has been reported to invade in an endothelial cell model (3), and causes invasive infections in infant rats after oral challenge (7), a situation that parallels human neonatal disease. An unencapsulated spontaneous mutant of RS218, RS218cap ${ }^{-}$, was also obtained from Dr. Silver and was used for epithelial cell invasion studies. Four additional K1 clinical isolates from neonates at Children's Hospital and Regional Medical Center (Seattle, WA, U.S.A.) were tested in transcytosis assays. Salmonella typhimurium LT-2 and E. coli HB101 were used as positive and negative control strains for invasion assays $(4,9)$. All bacteria were stored in skim milk at $-80^{\circ} \mathrm{C}$ and freshly subcultured 24 to $48 \mathrm{~h}$ before performance of assays. Liquid cultures of bacteria were grown in Luria-Bertani broth (10) at $37^{\circ} \mathrm{C}$ with shaking at $200 \mathrm{cpm}$. Bacteria were also grown on Luria-Bertani agar or MacConkey agar plates at $37^{\circ} \mathrm{C}$.

Cell lines, media, and culture conditions. The cell lines used were obtained from ATCC (Rockville, MD, U.S.A.). They included Caco-2 cells (ATCC HTB37), T84 cells (ATCC CCL248), A549 cells (ATCC CCL185), HEp-2 cells (ATCC CCL23), and MDCK cells (ATCC CCL34). Tissue culture medium was MEM plus 10\% FCS for Caco-2, MDCK, and HEp-2 cells, Ham's F12 medium and MEM (1:1) plus 10\% FCS for T84 cells, and RPMI plus 10\% FCS for A549 cells. Cells were used between passage 7 and 12 in our laboratory after receipt from ATCC. All cell lines were maintained in $25-\mathrm{cm}^{2}$ screw cap flasks at $37^{\circ} \mathrm{C}$ in a $5 \% \mathrm{CO}_{2}$ incubator. Monolayers were trypsinized and split (ratio, 1:6 for A549 cells, 1:4 for all other cell lines) upon reaching confluence.

Epithelial cell invasion assay. The gentamicin protection assay described by Isberg and Falkow (5) was used to examine cellular invasion in vitro for all cell lines tested. Briefly, epithelial cells were grown to confluence in 24-well tissue culture plates and used for quantitative invasion assays. The number of eukaryotic cells seeded per well and recovered after growth to confluence was determined by quantitation in a counting chamber. The number of eukaryotic cells seeded into each well was $5 \times 10^{4}$. The average number of days to confluence was 7 for Caco-2 and T84, 1 for A549, 3 for HEp-2, and 5 for MDCK cells. Each well was inoculated with bacterial cells grown to mid logarithmic phase (OD at $600 \mathrm{~nm}, 0.6$ ), washed in PBS, pH 7.0 (PBS), and diluted $1: 10^{4}$ in tissue culture medium. The target inoculum was $10^{5} \mathrm{CFU}$ except for the variable inoculum experiments, in which the maximum target inoculum was $10^{8} \mathrm{CFU}$. The infected cell monolayers were centrifuged at $800 \times g$ and incubated at $37^{\circ} \mathrm{C}$ in $5 \% \mathrm{CO}_{2}$. After $2 \mathrm{~h}$ of incubation, the monolayers were washed free of nonadherent bacteria, and tissue culture medium containing $100 \mu \mathrm{g}$ of gentamicin per milliliter was added for $2 \mathrm{~h}$ to kill extracellular organisms. Control experiments using bacteria grown in tissue culture medium in 24-well plates without eukaryotic cells demonstrated that incubation with this concentration of gentamicin for $2 \mathrm{~h}$ resulted in $>99.99 \%$ killing. After incubation with the antibiotic, the monolayers were washed, trypsinized, and lysed with $0.1 \%$ Triton X-100. The number of CFU recovered per well was determined by quantitative culture. All assays were performed in triplicate three to four times. The invasion frequency was calculated using the following equation: [organisms recovered $(\mathrm{CFU} / \mathrm{mL}) /$ organisms inoculated $(\mathrm{CFU} / \mathrm{mL})] \times 100=\%$ invasion. The same assay was used to determine the relative importance of inoculum size and whether the uptake of organisms was saturable. A range of 10 -fold dilutions $\left(10^{-1}\right.$ to $\left.10^{-4}\right)$ was plated, the total number of organisms recovered was quantified, and the invasion frequency was calculated.

Potential inhibitors of microfilament and microtubule integrity were tested to examine the role of the cytoskeleton on the uptake of strain RS218 into T84 cells. Inhibitors were incubated with the cell monolayer for $30 \mathrm{~min}$ before the addition of bacteria and continued throughout the 2-h incubation period. Both cytochalasin D, an inhibitor of microfilament formation, and colchicine, a disrupter of microtubules, were examined in this model. Each inhibitor was tested in triplicate. Data are expressed as the percent invasion normalized to the control (RS218 invasion in the absence of inhibitor $=100 \%$ ). $\mathrm{Cy}-$ tochalasin $\mathrm{D}$ was used in concentrations of $0.1,0.2,0.5,1.0$, and $2 \mu \mathrm{g} / \mathrm{mL}$, colchicine in concentrations of $1,2,4$, and 10 $\mu \mathrm{g} / \mathrm{mL}$. Viability of T84 cells was assessed by trypan blue exclusion.

Transcytosis assay. A transcytosis assay was also used to examine the ability of $E$. coli $\mathrm{K} 1$ to invade polarized monolayers of T84 or Caco- 2 cell (6). For these studies, $1 \times 10^{4}$ eukaryotic cells in $0.2 \mathrm{~mL}$ of tissue culture medium were seeded onto the apical side of $0.6-\mathrm{cm}^{2}$ polycarbonate transwell membranes, pore size $3 \mu \mathrm{m}$ (Millipore, Bedford, MA, U.S.A.). The basolateral chambers contained $1 \mathrm{~mL}$ of medium that was changed every $3 \mathrm{~d}$. Transepithelial cell electrical resistance was measured using a Millicell-ERS resistance system (Millipore). It took an average of $14 \mathrm{~d}$ for the T84 cells and $11 \mathrm{~d}$ for the Caco-2 cells to form intact polarized monolayers based on resistance $\left(\mathrm{ohms}-\mathrm{cm}^{2}\right)$. The transwell membranes were washed in sterile PBS and refed with fresh tissue culture medium. 
Resistance was measured, and $0.3 \mathrm{~mL}$ of bacterial suspension (inocula prepared as for gentamicin protection assay) was applied to the apical chamber. At each time point $(1,2,3$, and $4 \mathrm{~h}$ incubation), the lower chamber was sampled for quantitation. After sampling, the transwell membranes with the bacterial inoculum in the upper chamber were transferred to a new well containing fresh medium in the basolateral chamber. Thus, quantitation at each time was only those organisms that had undergone transcytosis of the polarized epithelium in the previous hour. For coinfection studies, equal numbers of $\mathrm{CFU}$ of the E. coli $\mathrm{K} 1$ isolate and $\mathrm{HB} 101$ were combined and applied to the apical surface. The recovered organisms were differentiated by lactose fermentation on MacConkey agar.

Brush border enzyme assays. Both gentamicin protection assays and transcytosis assays using Caco-2 cells were performed at different times $(4,7,11,14$, and $17 \mathrm{~d})$ to assay the effects of polarization and differentiation upon invasion. Brush border enzymes were harvested from Caco-2 cells at each of these times according to the method of Rousset et al. (11), with the modification that cells were disrupted by passage through a French pressure cell rather than by tissue grinding and sonication. Briefly, the cells from two $25-\mathrm{cm}^{2}$ flasks were harvested with trypsin/EDTA and washed three times in PBS at $4^{\circ} \mathrm{C}$. All subsequent manipulations were performed at $4^{\circ} \mathrm{C}$. The cell pellet was resuspended in $4 \mathrm{~mL}$ of PBS and passed through a French pressure cell twice at 20,000 psi. Solid $\mathrm{CaCl}_{2}$ was added to a final concentration of $10 \mathrm{mM}$, and the sample was spun for $10 \mathrm{~min}$ at $950 \times \mathrm{g}$. The supernatant was harvested and spun for $30 \mathrm{~min}$ at $33,500 \times \mathrm{g}$, and the subsequent pellet was resuspended in distilled water using a bath sonicator. Protein concentration was assayed according to the method of Lowry et al. (12). Sucrase-isomaltase activity was measured according to the method of Messer and Dahlqvist (13). Briefly, a solution of $100 \mathrm{U} / \mathrm{mL}$ of glucose oxidase, $100 \mu \mathrm{g} / \mathrm{mL}$ horseradish peroxidase, and $0.1 \% o$-dianisidine in $0.5 \mathrm{M}$ Tris, $\mathrm{pH} 6.0$, was added to $5 \mu \mathrm{g}$ of the protein extracted from Caco- 2 cells, in duplicate. Sucrose was added to each tube to a final concentration of $0.031 \mathrm{M}$, the tubes incubated at $37^{\circ} \mathrm{C}$, and the reactions stopped at 15 and $75 \mathrm{~min}$ by the addition of $100 \mu \mathrm{L}$ of $50 \% \mathrm{H}_{2} \mathrm{SO}_{4}$. The OD was read at $530 \mathrm{~nm}$, and the sucrase activity was calculated based on the amount of glucose present in the reaction at 75 min compared with 15 min (13). Alkaline phosphatase activity was assayed according to Garen and Levinthal (14) using $p$-nitrophenyl phosphate as substrate. Activities for both enzymes were expressed as milliunits per milligram of brush border proteins. These assays were performed in duplicate in conjunction with invasion and transcytosis assays on the same cell passages at the same times.

Electron microscopy. To assess whether E. coli invasion observed in the gentamicin protection assay represented true intracellular parasitism or just adherence, transmission electron microscopy of infected monolayers was performed as previously described (15). After the initial 2-h incubation with bacteria in the 24-well tissue culture plates, cells were washed once gently in $500 \mu \mathrm{L}$ of tissue culture medium at $37^{\circ} \mathrm{C}$ and fixed immediately in the wells with $2.5 \%$ glutaraldehyde for $2 \mathrm{~h}$. Cells were washed once with $0.1 \mathrm{M}$ sodium cacodylate buffer ( $\mathrm{pH} 7.4$ ), postfixed with $2 \%$ osmium tetroxide in distilled water, dehydrated in a graded series of ethanol, and embedded in Eponate 12 (Ted Pell, Inc., Redding CA, U.S.A.). After sectioning, the cells were stained with uranyl acetate and lead citrate and examined with a PJEOL JEM 1200 EX electron microscope (Jeol Ltd., Tokyo, Japan) at $80 \mathrm{kV}$.

\section{RESULTS}

Invasion of tissue culture monolayers. The results of gentamicin protection assays performed using MDCK, HEp-2, A549, Caco-2, and T84 cell lines are presented in Table 1. The inoculum, the number of organisms recovered, and the percent invasion is listed for each bacterial strain in each cell line. The numbers represent the mean \pm SD for three or four experiments repeated in triplicate. The Wilcoxon rank sum test was used to examine the significance of the differences noted between the invasion frequency of the E. coli $\mathrm{K} 1$ strain, RS218, and the negative control strain, HB101. Based on percent invasion, RS218 appeared to readily invade HEp-2, T84, and A549 cells, but not Caco-2 and MDCK cells. For HEp-2 cells, the invasion frequency was similar between RS218 and the positive control strain, LT-2. In other cell lines,

Table 1. Invasion of epithelial cell lines assayed by gentamicin protection

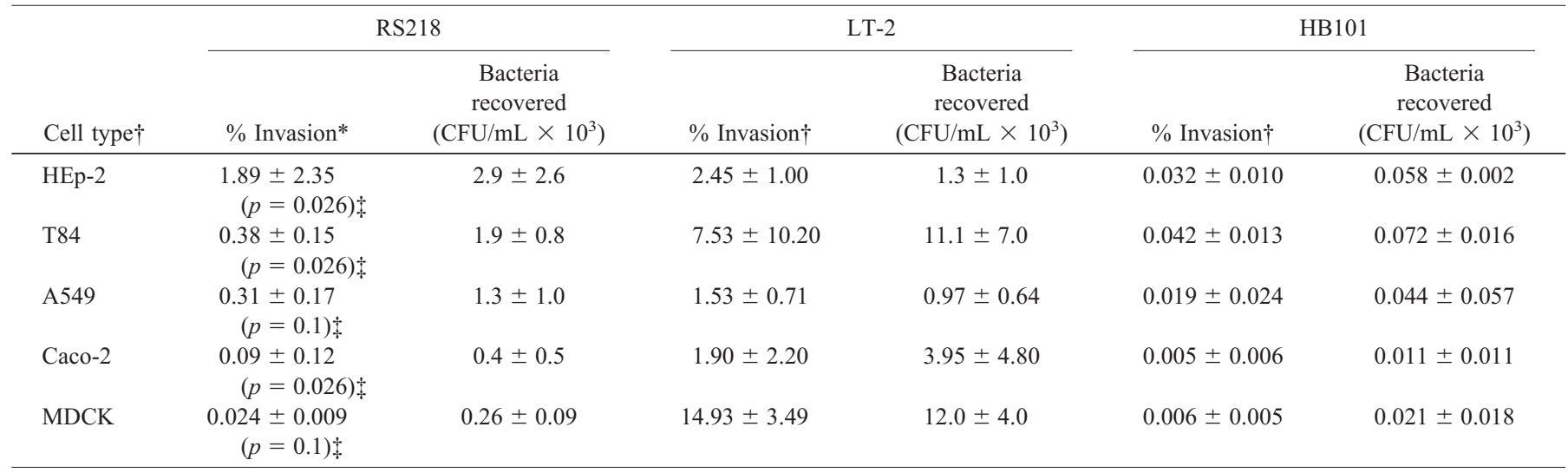

$* \%$ invasion $=[$ organisms recovered $(\mathrm{CFU} / \mathrm{mL}) /$ organisms inoculated $(\mathrm{CFU} / \mathrm{mL})] \times 100$.

$\dagger$ Each row is the mean of three to four experiments performed in triplicate for each cell line.

$\ddagger p$ value for comparison of RS218 with HB101 was calculated using Wilcoxon rank sum statistic. 
the invasion frequency for RS218 was intermediate between that for LT-2 and that for HB101. For HEp-2, T84, and Caco-2 cells lines, RS218 was significantly more invasive than HB101 $(p=0.026)$, and for A549 and MDCK cell lines there was a trend toward statistical significance $(p=0.1)$ RS218cap ${ }^{-}$, the unencapsulated mutant, was also tested with both A549 and Caco- 2 cells in the gentamicin protection assay and demonstrated invasion frequencies quite similar to the parent strain, RS218 (data not shown).

Because of interest in the ability of $E$. coli $\mathrm{K} 1$ to invade gastrointestinal epithelial cells, further studies were performed to confirm the significance of the intermediate amount of invasiveness demonstrated. These studies included experiments with variable inocula to look for a saturation effect, examination of the effect of microfilament and microtubule inhibitors, transcytosis assays, and electron microscopy, using intestinal cell lines.

Effect of inoculum on invasion frequency. For a selected cell line, T84, experiments were performed using variable inocula to examine the effect of inoculum on invasion (Table 2). The number of intracellular organisms recovered after the gentamicin protection assay appeared to reach a maximum at an inoculum of approximately $10^{7} \mathrm{CFU} / \mathrm{mL}$, resulting in an apparent decrease in the calculated invasion frequency from $0.4 \%$ at an inoculum of $5.8 \times 10^{6}$ to $0.02 \%$ at an inoculum of $2.9 \times 10^{8}$.

Effect of microfilament and microtubule inhibitors. The effect of cytochalasin D, a microfilament inhibitor, on T84 cell invasion by $\mathrm{RS} 218$ is shown in Figure $1 \mathrm{~A}$. The invasion frequency is decreased approximately $65 \%$ with the addition of $0.1 \mu \mathrm{g} / \mathrm{mL}$ of cytochalasin $\mathrm{D}$ and nearly $90 \%$ by the addition of $0.5 \mu \mathrm{g} / \mathrm{mL}$. However, colchicine, an inhibitor of microtubules, appears to have no effect on the invasion of T84 cells by strain RS218 (Fig. 1B). Thus, microfilaments, but not microtubules, appear to play a role in the internalization of $E$. coli K1.

Transcytosis of polarized gastrointestinal epithelial cells. To confirm that the results demonstrated in monolayers represented true cellular invasion, standard transcytosis assays were performed using Caco-2 or T84 cells grown on filter supports. These cell lines were chosen because of their ability to form polarized monolayers with tight junctions and because of their origin in the gastrointestinal epithelium, the hypothesized initial site of $E$. coli $\mathrm{K} 1$ invasion. Table 3 shows the results of transcytosis assays. Strain RS218 and the positive and negative

Table 2. Effect of inoculum on invasion frequency of strain RS218 in T84 cells

\begin{tabular}{lcc}
\hline Inoculum & Recovered & \% Invasion* \\
\hline $5.8 \times 10^{4}$ & $4.9 \times 10^{2}$ & 0.8 \\
$2.9 \times 10^{5}$ & $1.0 \times 10^{3}$ & 0.3 \\
$5.8 \times 10^{5}$ & $2.6 \times 10^{3}$ & 0.4 \\
$2.9 \times 10^{6}$ & $6.7 \times 10^{3}$ & 0.2 \\
$5.8 \times 10^{6}$ & $2.3 \times 10^{4}$ & 0.4 \\
$2.9 \times 10^{7}$ & $2.8 \times 10^{4}$ & 0.1 \\
$5.8 \times 10^{7}$ & $5.7 \times 10^{4}$ & 0.1 \\
$2.9 \times 10^{8}$ & $6.2 \times 10^{4}$ & 0.02 \\
\hline
\end{tabular}

$* \%$ invasion $=$ [organisms recovered $(\mathrm{CFU} / \mathrm{mL}) /$ organisms inoculated $(\mathrm{CFU} / \mathrm{mL})] \times 100$.
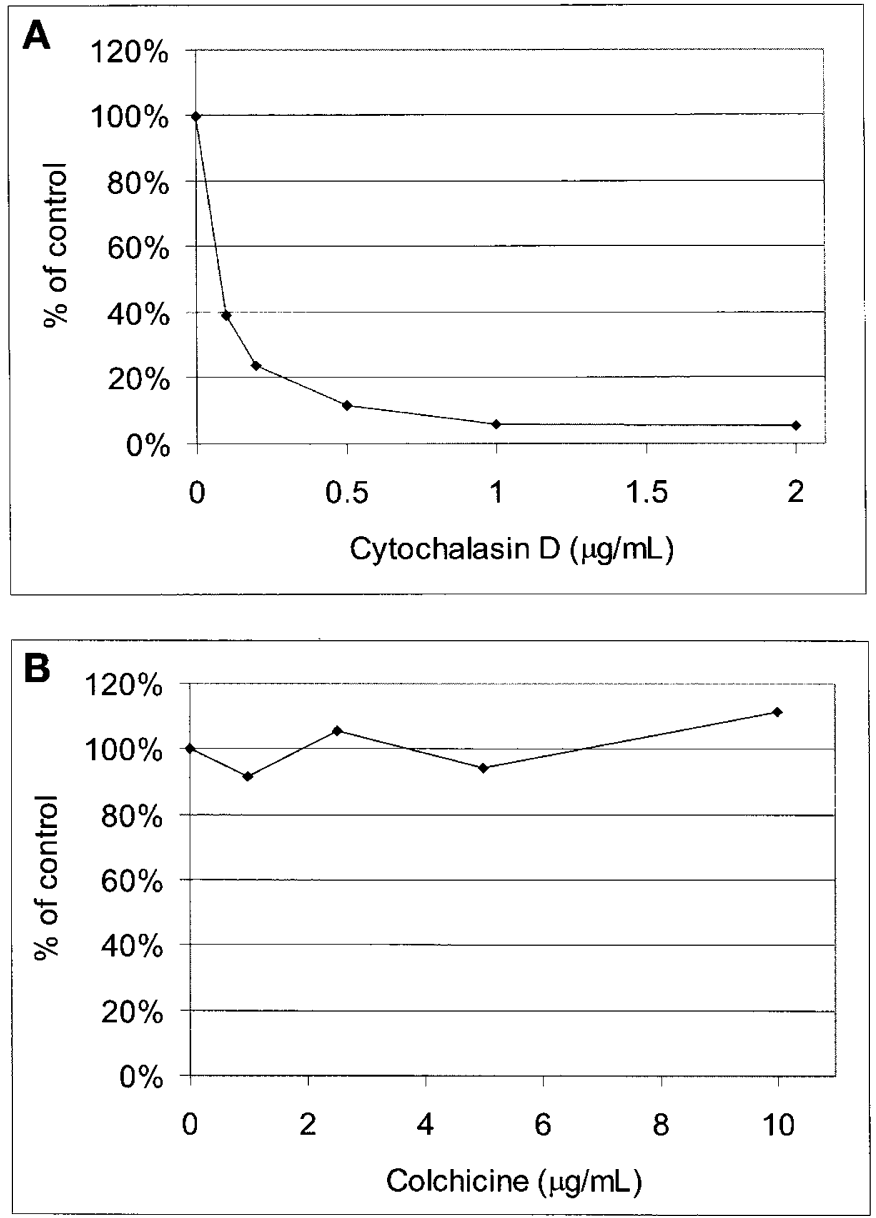

Fig. 1. Effect of cytochalasin $\mathrm{D}(A)$ and colchicine $(B)$ on the invasion of $\mathrm{T} 84$ cells by $E$. coli strain RS218. Each inhibitor was tested in triplicate. Data are expressed as the percent invasion normalized to the control (RS218 invasion in the absence of inhibitor $=100 \%$ ).

control strains, LT-2 and HB101, were inoculated separately onto transwell membranes, and transcytosis was assayed at 1, 2, 3, and $4 \mathrm{~h}$. In addition, HB101 was used in coinfection experiments with RS218 and LT-2 to control for leaky monolayers at each time (data not shown). For both Caco-2 and T84 cell monolayers, in the first $2 \mathrm{~h}$ of incubation RS218 demonstrated greater transcytosis than the positive control strain, LT-2. At 3 h, RS218 and LT-2 demonstrated a similar magnitude of transcytosis. At $4 \mathrm{~h}$ the integrity of the polarized membrane was apparently broken down as evidenced by both a decrease in resistance and the increased passage of the noninvasive control strain, HB101.

Transcytosis experiments were also performed using clinical isolates of $E$. coli from infants with invasive infection. Four K1 isolates from patients with bacteremia or meningitis were assayed using polarized T84 cells grown on filter supports. For each of the isolates, coinfection with HB101 was performed, and quantitation of differential recovery was made based on lactose fermentation on MacConkey agar. From resistance measurements, integrity of the polarized monolayer was maintained for approximately $3 \mathrm{~h}$. For all strains, the magnitude of transcytosis was similar to that seen with RS218, with between 
Table 3. Transcytosis of gastrointestinal epithelial cells

\begin{tabular}{|c|c|c|c|c|c|c|}
\hline & \multicolumn{2}{|c|}{ RS218 } & \multicolumn{2}{|c|}{ LT-2 } & \multicolumn{2}{|c|}{ HB101 } \\
\hline & $\mathrm{CFU} / \mathrm{mL}$ recovered & Resistance & $\mathrm{CFU} / \mathrm{mL}$ recovered & Resistance & $\mathrm{CFU} / \mathrm{mL}$ recovered & Resistance \\
\hline \multicolumn{7}{|l|}{ T84 cells } \\
\hline $0 \mathrm{~h}$ & $<10$ & 877 & $<10$ & 704 & $<10$ & 689 \\
\hline $1 \mathrm{~h}$ & $1.6 \times 10^{1}$ & 873 & $<10$ & 681 & $<10$ & 656 \\
\hline $2 \mathrm{~h}$ & $6.1 \times 10^{3}$ & 864 & $3.0 \times 10^{1}$ & 701 & $1.4 \times 10^{1}$ & 701 \\
\hline \multicolumn{7}{|l|}{ Caco-2 cells } \\
\hline Inoculum & $3.6 \times 10^{5}$ & NA & $2.8 \times 10^{5}$ & NA & $2.3 \times 10^{5}$ & NA \\
\hline $0 \mathrm{~h}$ & $<10$ & 1310 & $<10$ & 1150 & $<10$ & 1020 \\
\hline $1 \mathrm{~h}$ & $3.2 \times 10^{2}$ & 1120 & $2.1 \times 10^{2}$ & 1040 & $7.0 \times 10^{0}$ & 980 \\
\hline $2 \mathrm{~h}$ & $3.2 \times 10^{3}$ & 1010 & $2.1 \times 10^{2}$ & 997 & $1.2 \times 10^{1}$ & 1115 \\
\hline $3 \mathrm{~h}$ & $2.9 \times 10^{3}$ & 998 & $1.8 \times 10^{3}$ & 945 & $1.0 \times 10^{1}$ & 1016 \\
\hline
\end{tabular}

Abbreviation: NA, not applicable.

$2.5 \times 10^{3}$ and $5.7 \times 10^{5} \mathrm{CFU} / \mathrm{mL}$ recovered from the lower chamber at $2 \mathrm{~h}$ and no evidence of passage of strain HB101.

Effect of polarization and differentiation on invasion by $\mathbf{E}$. coli $K 1$. It was noted during performance of gentamicin protection assays that invasion of Caco- 2 cells was highly variable and that this variability seemed to correlate with the amount of time elapsed after confluence was achieved (data not shown). Cells typically grew to confluence after 5 to $6 \mathrm{~d}$ in culture and were used up to 1 wk after confluence was achieved. Because Caco-2 cell polarization and differentiation have been identified as factors in invasion by several bacterial species $(16,17)$, a series of experiments was performed to test the effect of time in culture of Caco-2 cells on invasion by E. coli $\mathrm{K} 1$ strain, RS218. Times were selected to represent active growth (d 4), confluence (d 7), polarization (d 11), and differentiation (d 14 to 17) (18). Standard gentamicin protection assays and brush border enzyme assays were performed at each time using Caco-2 cells grown in monolayers (Table 4). Maximum invasion by RS218 (and the greatest log difference from the negative control strain, HB101) was demonstrated at d 11 with a dramatic decrease at the later time points. Maximum enzyme activity for both sucrase and alkaline phosphatase appeared to peak at d 11 to 14 , suggesting that at this time cells were maximally differentiated (18). Transcytosis assays and monitoring of resistance were also performed at the same times (Table 5). Although cells appeared confluent at d 7, polarization, as demonstrated by resistance measurements, was not apparent until $\mathrm{d} 11$. This correlates with the ability of the negative control strain, HB101, to pass through the cells growing on filters at d 7, but not on d 11 or at later times.

Electron microscopy. Morphologic demonstration of intracellular organisms is the optimum method to confirm cellular invasion. Thus, electron microscopy of monolayers of Caco-2 and T84 cells infected with E. coli strains RS218 and HB101 and $S$. typhimurium strain LT-2 was performed. The results of the ultrastructural localization for E. coli K1 strain RS218 inside T84 cells are shown in Figures 2 and 3. The process of bacterial endocytosis is illustrated as follows. Organisms are first seen in close proximity to the epithelial cell surface (Fig. $2 A$ ), and then appear to be enveloped by the cell membrane (Fig. 2B). Multiple bacteria, each in a separate membranebound vacuole, can be seen internalized within a T84 cell (Fig. $2 C)$. Lysosomes are not observed in close proximity to the bacteria-containing vacuoles. At high magnification, intracellular RS218 are clearly demonstrated within membrane-bound vacuoles (Fig. 3). In Caco-2 cells the same sequence of internalization of E. coli $\mathrm{K} 1$ strain RS218 is observed, and intracellular bacteria are enclosed in membrane-bound vacuoles (Fig. 4). In this study, only single organisms were visible within each membrane-bound vacuole in both cell lines. The noninvasive $E$. coli strain, HB101, was not observed being internalized into either Caco-2 or T84 cells. The positive control, $S$. typhimurium strain LT-2, was found intracellularly with a frequency similar to RS218.

Table 4. Differentiation of $\mathrm{Caco}-2$ cells

\begin{tabular}{|c|c|c|c|c|c|}
\hline \multirow[b]{2}{*}{ Days in culture* } & \multicolumn{3}{|c|}{$\%$ Invasion $\dagger, \dot{\dagger}$} & \multirow{2}{*}{$\begin{array}{c}\text { Sucrase } \$ \\
\text { (mU/mg protein) }\end{array}$} & \multirow{2}{*}{$\begin{array}{c}\text { Alkaline } \\
\text { phosphatase } \\
\text { (mU/mg protein) }\end{array}$} \\
\hline & RS218 & LT-2 & HB101 & & \\
\hline 4 & 0.039 & 0.10 & 0.01 & 88.1 & 107 \\
\hline 7 & 0.022 & 0.35 & 0.02 & 240.3 & 182 \\
\hline 11 & 0.25 & 0.22 & 0.004 & 348.3 & 840 \\
\hline 14 & 0.01 & 0.88 & 0.006 & 311.7 & 700 \\
\hline 17 & 0.008 & 1.10 & 0 & 301.4 & 320 \\
\hline
\end{tabular}

* Caco-2 cells were seeded into either 24-well plates for P25 tissue culture flasks at the same inoculum and grown for the specified number of days before performance of gentamicin protection assays (24-well plates) or enzyme extraction and quantitation (P25 flasks).

$\dagger \%$ invasion $=[$ organisms recovered $(\mathrm{CFU} / \mathrm{mL}) /$ organisms inoculated $(\mathrm{CFU} / \mathrm{mL})] \times 100$.

$\ddagger$ Numbers for $\%$ invasion and enzyme assays represent the mean of two separate experiments at each time. 
Table 5. Polarization of Caco-2 cells

\begin{tabular}{cccc}
\hline Days in culture* & $\begin{array}{c}\text { Inoculum } \dagger \\
(\mathrm{CFU} / \mathrm{mL})\end{array}$ & $\begin{array}{c}\text { Recovered } \dagger \\
(\mathrm{CFU} / \mathrm{mL})\end{array}$ & $\begin{array}{c}\text { Resistance } \\
\left(\mathrm{ohms} / \mathrm{cm}^{2}\right)\end{array}$ \\
\hline 4 & $3.4 \times 10^{6} / 5.2 \times 10^{5}$ & $8.9 \times 10^{5} / 9.0 \times 10^{4}$ & 176 \\
7 & $9.7 \times 10^{5} / 3.1 \times 10^{5}$ & $2.3 \times 10^{5} / 8.0 \times 10^{4}$ & 203 \\
11 & $1.8 \times 10^{5} / 1.7 \times 10^{5}$ & $1.2 \times 10^{5} / 0$ & 666 \\
14 & $2.1 \times 10^{6} / 5.5 \times 10^{5}$ & $2.5 \times 10^{5} / 0$ & 623 \\
17 & $2.6 \times 10^{5} / 2.2 \times 10^{5}$ & $>10^{6} / \mathrm{ND} \dagger$ & 196 \\
\hline
\end{tabular}

* Caco-2 cells were inoculated onto membrane supports and incubated for the specified number of days prior to measurement of resistance and performance of transcytosis assays.

$\dagger$ Co-infection experiments with inocula of RS218 and HB101 combined in single filter wells; differential recovery at $2 \mathrm{~h}$ was quantitated by lactose fermentation on MacConkey agar. Expressed as RS218/HB101.

$\ddagger$ Too many lactose-fermenting RS218 were growing on the plates to permit accurate quantitation of the non-lactose-fermenting HB101.

Abbreviation: ND, not determined.

\section{DISCUSSION}

E. coli $\mathrm{K} 1$, although it causes invasive bacterial infections, including bacteremia and meningitis in neonates, has not been traditionally thought of as an intracellular pathogen or an organism that can invade the gastrointestinal epithelium. However, $E$. coli $\mathrm{K} 1$ is a normal inhabitant of the gastrointestinal tract, and it causes infections at distant sites, most frequently by bacteremic spread. This suggests that the likely portal of entry is via the gastrointestinal mucosa. E. coli that cause intestinal infections, such as ETEC, enteropathogenic E. coli, enteroinvasive $E$. coli, and enterohemorrhagic $E$. coli, have all been demonstrated to penetrate gastrointestinal epithelial cells in vitro (18-23). In addition, E. coli isolates that cause septicemic disease in calves have been demonstrated to be invasive (24). These findings caused us to hypothesize that invasion of gastrointestinal epithelial cells may have an important role in the pathogenesis of bacteremic neonatal $E$. coli $\mathrm{K} 1$ infections.

Recent reports have focused on the ability of E. coli K1 isolates from infants with meningitis to invade both primary cultures of bovine and human brain microvascular endothelium and an immortalized human umbilical vein endothelial cell line, EA-hy926 $(3,4,25)$. In primary brain endothelium, the same E. coli K1 strain used in our studies, RS218, demonstrated an invasion frequency of $0.1 \%$ (3). Invasion of the umbilical vein cell line, EA-hy926, by an unrelated $E$. coli $\mathrm{K} 1$ strain, IHE3034, was of similar magnitude, $0.46 \%$ (4). Meier et al. (4) also demonstrated that IHE3034 was able to invade bladder and kidney epithelial cell lines in vitro, but not Caco-2 cells. This was an unexpected finding because of the hypothesized pathogenesis of E. coli $\mathrm{K} 1$ infections in neonates, beginning with gastrointestinal tract colonization, followed by invasion of gastrointestinal epithelium and dissemination into the bloodstream and, frequently, by seeding of the CNS. This last step is presumably the result of invasion of brain microvascular endothelial cells.

Our initial experiments using multiple cell lines grown in monolayers in 24-well tissue culture plates suggested that RS218 was able to invade both of the gastrointestinal cell lines tested, Caco-2 and T84. The invasiveness, although of the same order of magnitude as the invasion frequency reported for endothelial cells, was not as great as that demonstrated for the

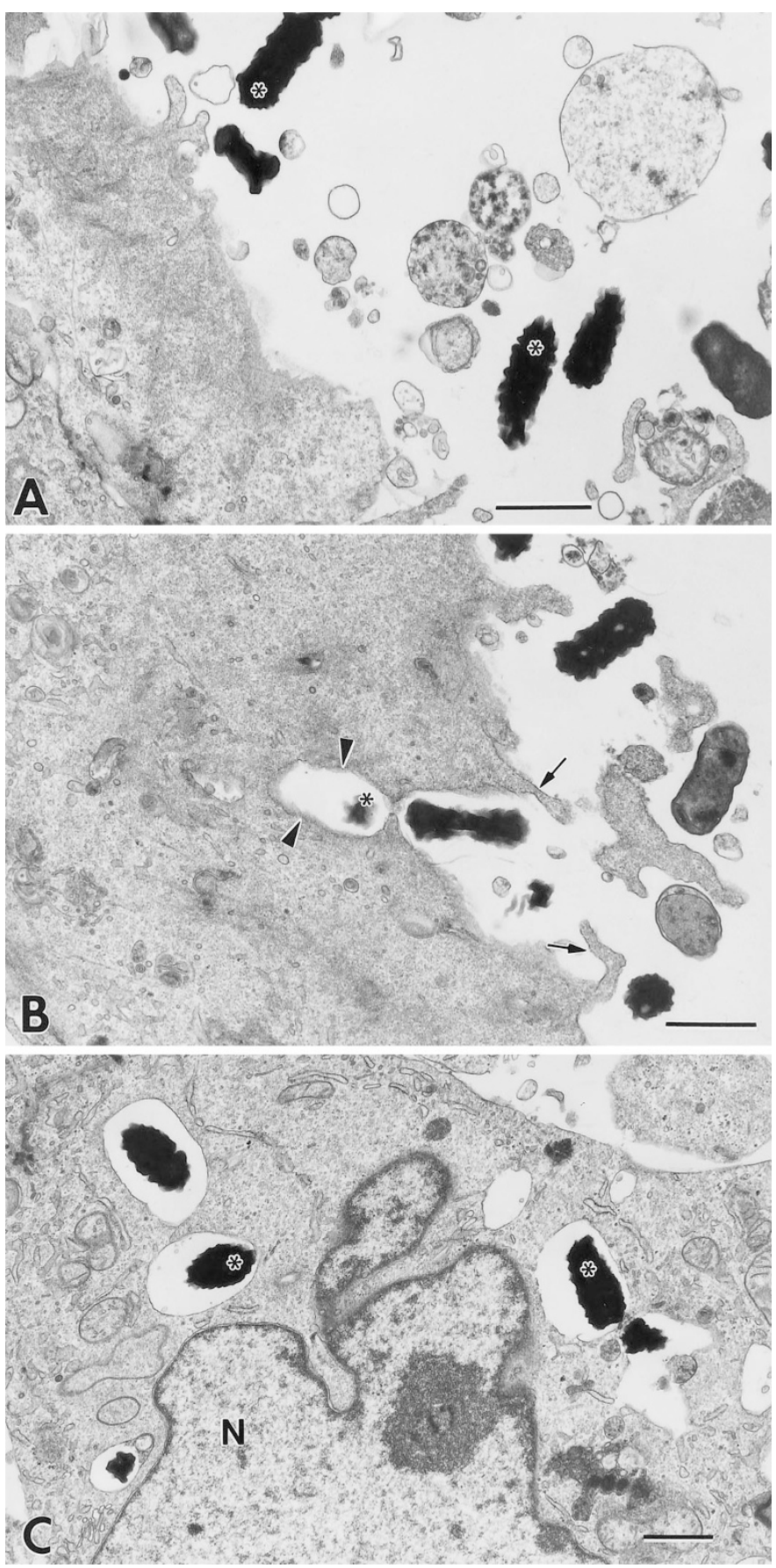

Fig. 2. Electron micrographs illustrate invasion of E. coli strain RS218 into T84 cells. $A, \mathrm{RS} 218$ bacteria $(*)$ are in close proximity to the cell surface. $B$, a bacterium is in enveloped by the cell surface microvilli (arrows). A portion of another bacterium (*) is visible completely enclosed in a membrane bound vacuole (arrowheads). C, several bacteria (*) are seen within this cell. Each membrane-bound vacuole contains a single RS218 bacterium. $N$, nucleus. Scale bar $1 \mu \mathrm{m}$.

positive control strain, LT-2, nor as great as that reported for the bladder epithelial cell line. However, saturation experiments and transmission electron microscopy confirmed that epithelial cell monolayers were being invaded by strain RS218. Further assays using Caco-2 and T84 cells grown in polarized monolayers on permeable supports demonstrated significant transcytosis of both cell lines. Transcytosis of Caco-2 cells has 


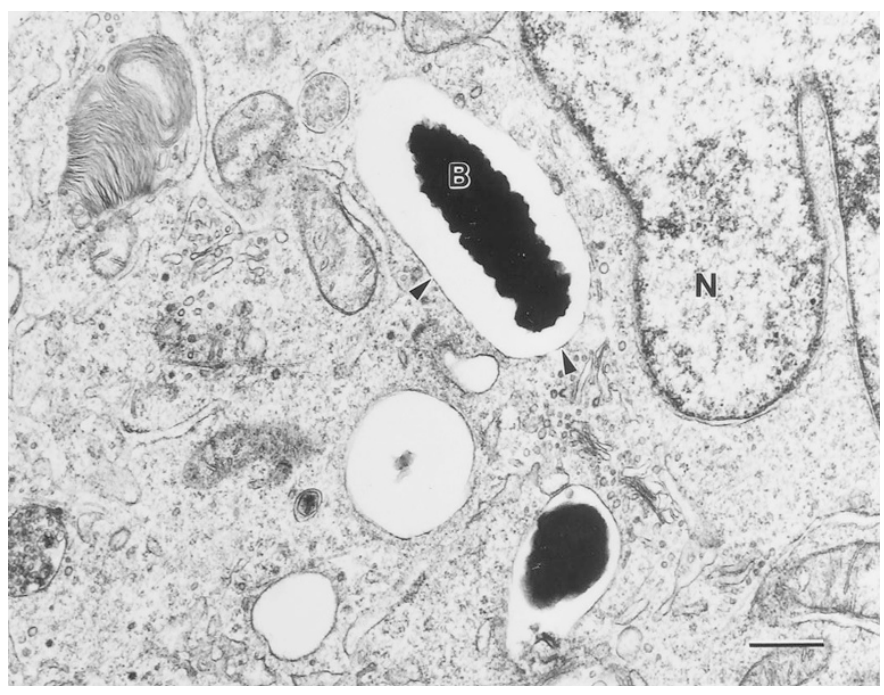

Fig. 3. A high-magnification micrograph illustrating E. coli K1 (RS218) inside a T84 cell. Each bacterium $(B)$ is enclosed in a membrane-bound vacuole (arrowheads). Lysosomal granules are not seen in contact with bacteriacontaining vacuoles, and the vacuoles do not show any electron-dense lysosomal material. $N$, nucleus. Scale bar $500 \mathrm{~nm}$.

also been demonstrated using a strain of E. coli that was isolated from a premature infant with necrotizing enterocolitis (26). Although the capsular type of this organism was not reported, the strain was not an ETEC, enteroinvasive E. coli, enteropathogenic $E$. coli, enterohemorrhagic $E$. coli, or enteroaggregative strain or a strain with a diffuse adherence phenotype.

Possible reasons for the marked difference between the results of Caco-2 invasion studies reported here and those of Meier et al. (4) that showed no invasion of Caco-2 cells include both a difference in methodology and a difference in the degree of differentiation, a well-described property of Caco-2 cells, which can impact invasion $(16,17)$. With regard to technique,

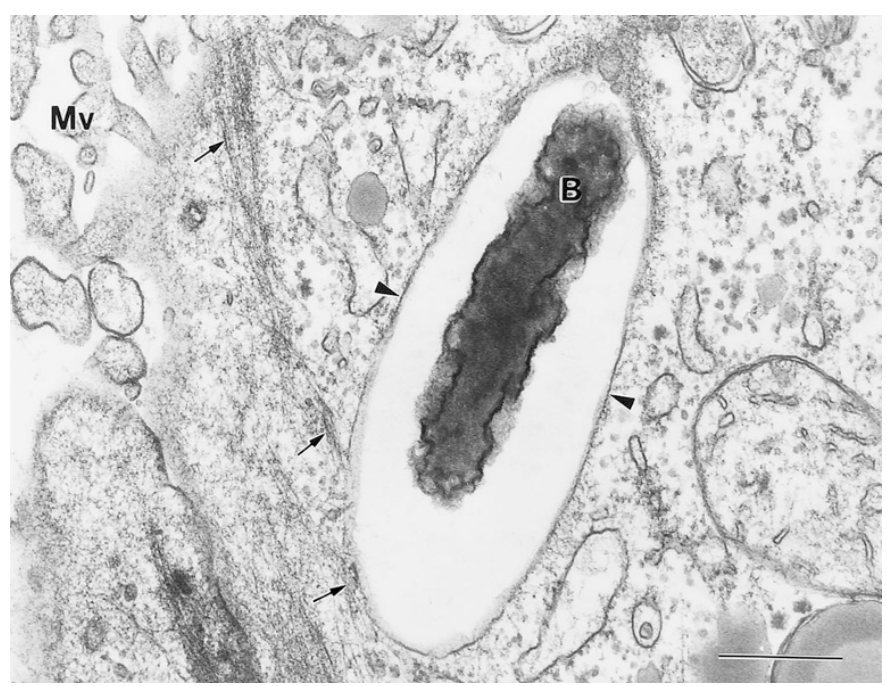

Fig. 4. An RS218 bacterium is demonstrated intracellularly within a Caco-2 cell. The bacterium $(B)$ is bounded by a membrane-formed vacuole (arrowheads) located close to the cell surface. Bundles of microfilaments are observed at the cell surface and closely associated with the vacuole (arrows). $M v$, microvilli. Scale bar $500 \mathrm{~nm}$.
Meier et al. (4) used both a higher inoculum and a longer incubation period for their studies. Our data presented here demonstrated that increasing the inoculum will result in a lower apparent invasion frequency. This artifactual lowering of invasiveness can be corrected by using an inoculum within the linear range, which we did. The use of a longer incubation time may also cause a lowering of apparent invasion frequency if organisms are able to both invade and exit via the apical membrane.

Most important in evaluating invasion of Caco-2 cells appears to be the length of time they are grown in culture, which regulates their degree of differentiation and polarization (11, 18). Proliferation usually does not begin until after a lag period of $48 \mathrm{~h}$. Caco- 2 cells typically require 5 to $6 \mathrm{~d}$ in culture to become confluent. Once confluent, polarization begins (usually complete at d 9 to 11). Differentiation occurs slightly later and is usually completed by d 15 to 20 in culture. Meier et al. (4) used Caco-2 cells grown in monolayers that had been seeded only $24 \mathrm{~h}$ before performing their assays and, thus, were unlikely to be either polarized or differentiated. Both polarization and differentiation of Caco-2 cells are important for invasion by different bacterial species. Bacteria that require polarization of monolayers, but not differentiation include Yersinia pseudotuberculosis (16) and Listeria monocytogenes (17). Bacteria that bind to receptors that are differentiation-related include ETEC (27) and Salmonella (6). Our findings suggest that both polarization and differentiation may be needed for invasion of E. coli $\mathrm{K} 1$ into Caco-2 cells. The peaking of the invasion frequency at $11 \mathrm{~d}$ in culture correlates both with polarization, based on resistance, and with differentiation, based on brush border enzyme activity. The very narrow window during which maximal invasion occurs suggests that a specific receptor required for E. coli K1 may be produced during the early phases of differentiation.

The phenomenon we described in vitro may have an in vivo correlate. An excellent animal model exists for the early steps of pathogenesis in neonates, the infant rat model of bacteremia after oral inoculation of organisms (28). In this model, strain RS218 has been demonstrated to cause bacteremia in $60 \%$ of newborn rats (7). The susceptibility to invasiveness with E. coli $\mathrm{K} 1$ infection was examined in rats ranging from 3 to $30 \mathrm{~d}$ of age (28): the incidence of bacteremia dropped from $68 \%$ at $5 \mathrm{~d}$ to $10 \%$ at $15 \mathrm{~d}$ and $0 \%$ at $30 \mathrm{~d}$. This parallels the disease incidence in human infants. Numerous investigators have identified unique characteristics of the gastrointestinal tract of newborns compared with older children and adults, including decreased quantities of secretory $\operatorname{IgA}$, a more labile intraluminal $\mathrm{pH}$, physical and chemical differences in mucins, structural differences in microvillus membranes, and differing numbers and specificity of cell receptors. These characteristics have been suggested to affect the susceptibility of newborns to diarrhea-producing microorganisms and their toxins $(29,30)$ and may also increase the invasiveness of $E$. coli $\mathrm{K} 1$ in the neonatal gastrointestinal tract. The latter two observations may be significant relative to our findings about the importance of polarization and differentiation. If a specific gastrointestinal epithelial cell receptor for $E$. coli $\mathrm{K} 1$ was only produced in the 
immature gut, it would help explain the increased susceptibility to invasive $E$. coli $\mathrm{K} 1$ infection seen in neonates.

Both clinical isolates of $E$. coli $\mathrm{K} 1$ and an unencapsulated mutant of the laboratory strain were also demonstrated to undergo transcytosis in gastrointestinal epithelial cells. This is of importance when characterizing the role of invasion in the pathogenesis of systemic infections in neonates. These findings suggest that invasion is not an isolated phenomenon in laboratory strains, and it helps to demonstrate that the $\mathrm{K} 1$ capsule, although it may be important in evading clearance of the organisms once they have invaded, is not required for the invasive phenotype (7). The clustering of the invasion phenotype in strains with the K1 capsule may simply be another example of the clonality that is seen among E. coli strains causing neonatal septicemia and meningitis (31).

Transcytosis of gastrointestinal epithelium is a logical first step in the pathogenesis of neonatal E. coli $\mathrm{K} 1$ infection. Demonstration of the phenomenon in vitro, although compelling, needs to be confirmed in vivo. Because such a relevant animal model exists for the early steps of pathogenesis in neonates, it will be possible to test the hypotheses advanced here. Future experiments will focus on the identification of invasion mutants in vitro and testing their ability to invade in vivo. Ultimately these types of experiments will be required to fully understand the pathogenesis of neonatal $E$. coli $\mathrm{K} 1$ infections.

Acknowledgments. The authors thank Craig Rubens and Steve Moseley for technical advice and critical discussion during preparation of the manuscript.

\section{REFERENCES}

1. Robbins JB, McCracken Jr GH, Gotschlich EC, Orskov F, Orskov I, Hanson LA 1974 Escherichia coli $\mathrm{K} 1$ capsular polysaccharide associated with neonatal meningitis. N Engl J Med 290:1216-1220

2. Sarff LD, McCracken Jr GH 1975 Epidemiology of Escherichia coli K1 in healthy and diseased newborns. Lancet 1:1099-1104

3. Huang SH, Wass C, Fu Q, Prasadarao NV, Stins M, Kim KS 1995 Escherichia coli invasion of brain microvascular endothelial cells in vitro and in vivo :molecular cloning and characterization of invasion gene ibe10. Infect Immun 63:4470-4475

4. Meier C, Oelschlaeger TA, Merkert H, Korhonen TK, Hacker J 1996 Ability of Escherichia coli isolates that cause meningitis in newborns to invade epithelial and endothelial cells. Infect Immun 64:2391-2399

5. Isberg RR, Falkow S 1985 A single genetic locus encoded by Yersinia pseudotuberculosis permits invasion of cultured animal cells by Escherichia coli K-12. Nature 317:262-264

6. Finlay BB, Falkow S 1990 Salmonella interactions with polarized human intestinal Caco-2 epithelial cells. J Infect Dis 162:1096-1106

7. Silver RP, Vimr ER 1990 Polysialic acid capsule of Escherichia coli K1. In: Iglewski BH, Clark VL (eds) Molecular Basis of Bacterial Pathogenesis. Academic Press, San Diego, pp 39-60

8. Bloch CA, Orndorff PE 1990 Impaired colonization by and full invasiveness of Escherichia coli $\mathrm{K} 1$ bearing a site-directed mutation in the type 1 pilin gene. Infect Immun 58:275-278
9. Galan JE, Curtiss III R 1989 Cloning and molecular characterization of genes whose products allow Salmonella typhimurium to penetrate tissue culture cells. Proc Natl Acad Sci USA 86:6383-6387

10. Sambrook J, Fritsch EF, Maniatis T 1989 Molecular Cloning, A Laboratory Manual. Cold Spring Harbor Laboratory, Cold Spring Harbor, NY, pp A1

11. Rousset M, Laburthe M, Pinto M, Chevalier G, Rouyer-Fessard C, Dussaulx E, Trugnan G, Boige N, Brun JL, Zweibaum A 1985 Enterocytic differentiation and glucose utilization in the human colon tumor cell Caco-2: modulation by forskolin. J Cell Physiol 123:377-385

12. Lowry DH, Rosebough NJ, Farr AL, Randall RJ 1951 Protein measurement with the Folin phenol reagent. J Biol Chem 193:265-275

13. Messer M, Dahlqvist A 1966 A one-step ultramicro method for the assay of intestinal disaccharidases. Anal Biochem 14:376-392

14. Garen A, Levinthal C 1960 A fine-structure genetic and chemical study of the enzyme alkaline phosphatase of E. coli. Biochim Biophys Acta 38:470-483

15. Burns JL, Jonas M, Chi EY, Clark DK, Berger A, Griffith A 1996 Invasion of respiratory epithelial cells by Burkholderia (Pseudomonas) cepacia. Infect Immun 64:4054-4059

16. Coconnier MH, Bernet-Camard MF, Servin AL 1994 How intestinal epithelial cell differentiation inhibits the cell-entry of Yersinia pseudotuberculosis in colon carcinoma Caco-2 cell line in culture. Differentiation 58:87-94

17. Gaillard JL, Finlay BB 1996 Effect of cell polarization and differentiation on entry of Listeria monocytogenes into the enterocyte-like Caco-2 cell line. Infect Immun 64:1299-1308

18. Pinto M, Robine-Leon S, Appay MD, Kedinger M, Triadou N, Dussaulx E, Lacroix B, Simon-Assmann P, Haffen K, Fogh J, Zweibaum A 1983 Enterocyte-like differentiation and polarization of the human colon carcinoma cell line Caco-2 in culture. Biol Cell 47:323-330

19. Donnenberg MS, Donohue-Rolfe A, Keusch GT 1989 Epithelial cell invasion: an overlooked property of enteropathogenic Escherichia coli (EPEC) associated with the EPEC adherence factor. J Infect Dis 160:452-459

20. Donnenberg MS, Kaper JB 1992 Enteropathogenic Escherichia coli. Infect Immun 60:3953-3961

21. Elsinghorst EA, Kopecko DJ 1992 Molecular cloning of epithelial cell invasion determinants from enterotoxigenic Escherichia coli. Infect Immun 60:2409-2417

22. Elsinghorst EA, Weitz JA 1994 Epithelial cell invasion and adherence directed by the enterotoxigenic Escherichia coli tib locus is associated with a 104-kilodalton outer membrane protein. Infect Immun 62:3463-3471

23. Oelschlaeger TA, Barrett TJ, Kopecko DJ 1994 Some structures and processes of human epithelial cells involved in uptake of enterohemorrhagic Escherichia coli O157:H7 strains. Infect Immun 62:5142-5150

24. Korth MJ, Lara JC, Moseley SL 1994 Epithelial cell invasion by bovine septicemic Escherichia coli. Infect Immun 62:41-47

25. Prasadarao NV, Wass CA, Weiser JN, Stins MF, Huang SH, Kim KS 1996 Outer membrane protein A of Escherichia coli contributes to invasion of brain microvascular endothelial cells. Infect Immun 64:146-153

26. Panigrahi P, Bamford P, Horvath K, Morris Jr JG, Gewolb IH 1996 Escherichia coli transcytosis in a Caco-2 cell model: implications in neonatal necrotizing enterocolitis. Pediatr Res 40:415-421

27. Kerneis S, Chauviere G, Darfeuille-Michaud A, Aubel D, Coconnier MH, Joly B, Servin AL 1992 Expression of receptors for enterotoxigenic Escherichia coli during enterocytic differentiation of human polarized intestinal epithelial cells in culture. Infect Immun 60:2572-2580

28. Glode MP, Sutton A, Moxon ER, Robbins JB 1977 Pathogenesis of neonatal Escherichia coli meningitis: induction of bacteremia and meningitis in infant rats fed E. coli $\mathrm{K} 1$. Infect Immun 16:75-80

29. Cohen MB, Guarino A, Shukla R, Giannella RA 1988 Age-related differences in receptors for Escherichia coli heat-stable enterotoxin in the small and large intestine of children. Gastroenterology 94:367-373

30. Lencer WI, Chu SHW, Walker WA 1987 Differential binding kinetics of cholera toxin to intestinal microvillus membrane during development. Infect Immun 55:3126-3130

31. Selander RK, Korkhonen TK, Vaisanen-Rhen V, Williams PH, Pattison PE, Caugant DA 1986 Genetic relationships and clonal structure of strains of Escherichia coli causing neonatal septicemia and meningitis. Infect Immun 52:213-222 